\title{
Kv1.3 Channel as a Key Therapeutic Target for Neuroinflammatory Diseases: State of the Art and Beyond
}

\author{
Xiaoli Wang ${ }^{1,2+}$, Guoyi Li't, Jingkang Guo'2, Zhiping Zhang'2, Shuzhang Zhang'2, \\ Yudan Zhu' ${ }^{1}$, Jiwei Cheng ${ }^{1}$, Lu Yu' ${ }^{1}$, Yonghua Ji ${ }^{2,3 *}$ and Jie Tao ${ }^{1,4 *}$ \\ ${ }^{1}$ Department of Neurology and Central Laboratory, Putuo Hospital, Shanghai University of Traditional Chinese Medicine, \\ Shanghai, China, ${ }^{2}$ Institute of Biomembrane and Biopharmaceutics, Shanghai University, Shanghai, China, ${ }^{3}$ Xinhua \\ Translational Institute for Cancer Pain, Shanghai, China, ${ }^{4}$ Putuo Clinical Medical School, Anhui Medical University, Shanghai, \\ China
}

\section{OPEN ACCESS}

Edited by:

Francisco Lopez-Munoz, Camilo José Cela University, Spain

Reviewed by:

Christine Beeton,

Baylor College of Medicine,

United States

Jose Antonio Guerra,

Complutense University of Madrid,

Spain

*Correspondence:

Yonghua Ji

yhji@staff.shu.edu.cn

Jie Tao

jietao_putuo@foxmail.com

${ }^{\dagger}$ These authors have contributed equally to this work

Specialty section: This article was submitted to

Neuropharmacology, a section of the journal

Frontiers in Neuroscience

Received: 09 August 2019 Accepted: 10 December 2019

Published: 14 January 2020

Citation:

Wang X, Li G, Guo J, Zhang Z, Zhang S, Zhu Y, Cheng J, Yu L, Ji Y and Tao J (2020) Kv1.3 Channel as a Key Therapeutic Target for Neuroinflammatory Diseases:

State of the Art and Beyond.

Front. Neurosci. 13:1393.

doi: 10.3389/fnins.2019.01393
It remains a challenge for the effective treatment of neuroinflammatory disease, including multiple sclerosis (MS), stroke, epilepsy, and Alzheimer's and Parkinson's disease. The voltage-gated potassium Kv1.3 channel is of interest, which is considered as a novel therapeutic target for treating neuroinflammatory disorders due to its crucial role in subsets of $\mathrm{T}$ lymphocytes as well as microglial cells. Toxic animals, such as sea anemones, scorpions, spiders, snakes, and cone snails, can produce a variety of toxins that act on the Kv1.3 channel. The Stichodactyla helianthus $\mathrm{K}^{+}$channel blocking toxin (ShK) from the sea anemone $S$. helianthus is proved as a classical blocker of Kv1.3. One of the synthetic analogs ShK-186, being developed as a therapeutic for autoimmune diseases, has successfully completed first-in-man Phase 1 trials. In addition to addressing the recent progress on the studies underlying the pharmacological characterizations of ShK on MS, the review will also explore the possibility for clinical treatment of ShK-like Kv1.3 blocking polypeptides on other neuroinflammatory diseases.

Keywords: Kv1.3, ShK, neuroinflammatory disease, multiple sclerosis, stroke, epilepsy, Alzheimer's disease, Parkinson's disease

\section{INTRODUCTION}

Kv1.3 is a classical Shaker-type potassium channel with six transmembrane segments (Wulff and Zhorov, 2008), discovered in one of the non-excitable cells, T lymphocytes (Chiang et al., 2017), in the early 1980s. It is worth mentioning that Kv1.3 is the first $\mathrm{K}^{+}$channel to be identified outside electrically excitable tissues. Kv1.3 in T lymphocytes is responsible for controlling the membrane potential which is critical for the activation of these immune cells (Veytia-Bucheli et al., 2018). Several studies have confirmed that Kv1.3 is highly expressed in macrophages, microglia, and TEM cells, suggesting that Kv1.3 plays a crucial role in immune and inflammatory responses to human diseases such as multiple sclerosis (MS), rheumatoid arthritis, Type 1 diabetes, and asthma (Toldi et al., 2010; Huang et al., 2017; Tanner et al., 2017; Zhou et al., 2018). In these conditions, the expression of Kv1.3 channels is significantly elevated (Rangaraju et al., 2009), which is beneficial to define the role of Kv1.3 in autoimmune diseases as well as to clarify the significance of developing Kv1.3 blocker drugs. 
Toxin peptides from natural toxic animals are the largest family of ion channel blockers. They are becoming the medicinal arsenal for the treatment of various diseases including neuroinflammatory disorders. Toxin peptides targeting $\mathrm{Kv}$ channels have been isolated and identified so far (Zhao et al., 2015). Toxins derived from scorpion, sea anemone, snakes, and other animals are found to block Kv1.3 with different affinity and selectivity (Table 1 and Figure 1). The reference data for the described toxin polypeptides are from the Protein Data Bank $\operatorname{archive}^{1}$ (PDB). One of the most representative Kv1.3 blockers is sea anemone toxin peptides. Sea anemones have a rich source of peptide toxins acting on ion channels, which are presumably present in special spiny organelles (nematodes) (Madio et al., 2019). These toxins can be used to catch prey as well as defend against predators (Prentis et al., 2018). Up to now, a number of toxins have been isolated and purified from the venom of various species of sea anemones. Most of sea anemone toxins can be divided into three types: porous soluble cytins which can be inhibited by sphingolipin (Anderluh and Macek, 2002); neurotoxins acting on voltage-gated $\mathrm{Na}^{+}$

${ }^{1}$ https://www.rcsb.org/ channels (Norton, 1991); and the toxins acting on the voltagegated Kv1 channels (Norton, 1991; Castaneda et al., 1995), which have different molecular weights. Among these toxins, both $\mathrm{Na}^{+}$and $\mathrm{K}^{+}$channel peptide toxins are considered as useful tools for investigating both the structure and function of channels, even developing potential drugs for the treatment of ion channelopathies because of the high specific and affinity to target channels.

$\mathrm{K}^{+}$channel peptide toxins could be classified into three types based on the structural and functional differences. Type 1 potassium channel toxins include five members, ShK from Stichodactyla helianthus (Castaneda et al., 1995), BgK from Bunodosoma granulifera (Cotton et al., 1997), AeK from Actinia equina (Minagawa et al., 1998), and HmK from Heteractis magnifica (Gendeh et al., 1997), which can block Kv1 (Shaker) potassium channels. Type 2 potassium channel toxins include AsKC 1-3 (kalicludines 1-3) (Schweitz et al., 1995), which block Kv1 channels much less effectively than Type 1 toxins. Furthermore, Type 3 potassium channel toxins include BDS-I and II from Anemonia sulcata which can specific block Kv3.4 channels and APETx1 from Anthopleura elegantissima (Diochot et al., 1998, 2003). The alignment of homologous sequence

TABLE 1 | Examples of ShK-related natural venom peptides acting on Kv1.3.

\begin{tabular}{|c|c|c|c|c|c|}
\hline Peptide & Species & $\begin{array}{l}\text { Number of } \\
\text { residues }\end{array}$ & Disulfide pattern & $\mathrm{IC}_{50}$ or $\mathrm{K}_{\mathrm{d}}$ & Related diseases \\
\hline $\begin{array}{l}\text { Sea anemone toxin } \\
\text { ShK }\end{array}$ & $\begin{array}{l}\text { Stichodactyla } \\
\text { helianthus }\end{array}$ & 35 & $\begin{array}{c}\mathrm{C} 1-\mathrm{C} 6, \mathrm{C} 2-\mathrm{C} 4 \\
\mathrm{C} 3-\mathrm{C} 5\end{array}$ & $\begin{array}{l}133 \text { pM (Castaneda et al., } \\
\text { 1995) }\end{array}$ & $\begin{array}{l}\text { Psoriasis (Tarcha et al., 2017); multiple sclerosis } \\
\text { (Beeton et al., 2005); ischemic stroke (Peng } \\
\text { et al., 2014); Alzheimer's disease (Peng et al., } \\
\text { 2014) }\end{array}$ \\
\hline $\begin{array}{l}\text { Sea anemone toxin } \\
\text { BgK }\end{array}$ & $\begin{array}{l}\text { Bunodosoma } \\
\text { granuliferum }\end{array}$ & 37 & $\begin{array}{c}\mathrm{C} 1-\mathrm{C} 6, \mathrm{C} 2-\mathrm{C} 4 \\
\mathrm{C} 3-\mathrm{C} 5\end{array}$ & $\begin{array}{l}3.6 \pm 0.6 \text { nM (Aneiros et al. } \\
1993)\end{array}$ & Perhaps multiple sclerosis (Beraud et al., 2006) \\
\hline Scorpion toxin BmP02 & $\begin{array}{l}\text { Mesobuthus } \\
\text { martensii }\end{array}$ & 28 & $\begin{array}{c}\mathrm{C} 1-\mathrm{C} 4, \mathrm{C} 2-\mathrm{C} 5 \\
\mathrm{C} 3-\mathrm{C} 6\end{array}$ & $7.0 \pm 0.6 \mathrm{nM}$ (Zhu et al., 2012) & Perhaps multiple sclerosis (Wu et al., 2016) \\
\hline Scorpion toxin BmKTX & $\begin{array}{l}\text { Mesobuthus } \\
\text { martensii }\end{array}$ & 37 & $\begin{array}{c}\mathrm{C} 1-\mathrm{C} 4, \mathrm{C} 2-\mathrm{C} 5 \\
\text { C3-C6 }\end{array}$ & 200 pM (Renisio et al., 2000) & $\begin{array}{l}\text { Multiple sclerosis (Devaux et al., 2004); } \\
\text { Alzheimer's disease (Norton and Chandy, } \\
\text { 2017); Parkinson's disease (Tubert et al., 2016) }\end{array}$ \\
\hline $\begin{array}{l}\text { Scorpion defensin } \\
\text { BmKDfsin4 }\end{array}$ & $\begin{array}{l}\text { Mesobuthus } \\
\text { martensii }\end{array}$ & 37 & NR & 510.2 nM (Meng et al., 2016) & NR \\
\hline Scorpion toxin OSK1 & $\begin{array}{l}\text { Orthochirus } \\
\text { scrobiculosus }\end{array}$ & 38 & $\begin{array}{c}\mathrm{C} 1-\mathrm{C} 4, \mathrm{C} 2-\mathrm{C} 5 \\
\mathrm{C} 3-\mathrm{C} 6\end{array}$ & $\begin{array}{l}14.0 \pm 1.0 \text { pM (Mouhat et al., } \\
2005)\end{array}$ & $\begin{array}{l}\text { Multiple sclerosis (Tegla et al., 2011); } \\
\text { Alzheimer's disease (Tarcha et al., 2017) }\end{array}$ \\
\hline $\begin{array}{l}\text { Scorpion toxin } \\
\text { Kaliotoxin (KTX) }\end{array}$ & $\begin{array}{l}\text { Androctonus } \\
\text { mauritanicus }\end{array}$ & 38 & $\begin{array}{c}\mathrm{C} 1-\mathrm{C} 4, \mathrm{C} 2-\mathrm{C} 5 \\
\mathrm{C} 3-\mathrm{C} 6\end{array}$ & $\begin{array}{l}0.41 \pm 0.23 \text { nM (Gairi et al., } \\
1997)\end{array}$ & $\mathrm{NR}$ \\
\hline $\begin{array}{l}\text { Scorpion toxin } \\
\text { Charybdotoxin (ChTX) }\end{array}$ & $\begin{array}{l}\text { Leiurus } \\
\text { quinquestriatus }\end{array}$ & 37 & $\begin{array}{c}\mathrm{C} 1-\mathrm{C} 4, \mathrm{C} 2-\mathrm{C} 5 \\
\text { C3-C6 }\end{array}$ & $\begin{array}{l}0.71 \pm 0.19 \text { nM } \\
\text { (Gimenez-Gallego et al., 1988) }\end{array}$ & Multiple sclerosis (Hu et al., 2007) \\
\hline $\begin{array}{l}\text { Scorpion toxin } \\
\text { Maurotoxin (MTX) }\end{array}$ & $\begin{array}{l}\text { Scorpio } \\
\text { maurus }\end{array}$ & 34 & $\begin{array}{l}\mathrm{C} 1-\mathrm{C} 5, \mathrm{C} 2-\mathrm{C} 6 \\
\mathrm{C} 3-\mathrm{C} 4, \mathrm{C} 7-\mathrm{C} 8\end{array}$ & 180 nM (Kharrat et al., 1997) & Perhaps multiple sclerosis (Jensen et al., 2002) \\
\hline $\begin{array}{l}\text { Scorpion toxin } \\
\text { Noxiustoxin (NTX) }\end{array}$ & $\begin{array}{l}\text { Centruroides } \\
\text { noxius }\end{array}$ & 39 & $\begin{array}{c}\mathrm{C} 1-\mathrm{C} 4, \mathrm{C} 2-\mathrm{C} 5 \\
\text { C3-C6 }\end{array}$ & $\begin{array}{l}0.31 \pm 0.12 \text { nM (Sitges et al., } \\
1986)\end{array}$ & NR \\
\hline Scorpion toxin Pi1 & $\begin{array}{l}\text { Pandinus } \\
\text { imperator }\end{array}$ & 35 & $\begin{array}{l}\text { C1-C5, C2-C6, } \\
\text { C3-C7, C4-C8 }\end{array}$ & 11.4 nM (Péter et al., 2000) & NR \\
\hline Scorpion toxin Vm24 & Vaejovis smithi & 36 & $\begin{array}{l}\mathrm{C} 1-\mathrm{C} 5, \mathrm{C} 2-\mathrm{C} 6 \\
\mathrm{C} 3-\mathrm{C} 7, \mathrm{C} 4-\mathrm{C} 8\end{array}$ & 2.9 pM (Gurrola et al., 2012) & $N R$ \\
\hline Worm peptide AcK1 & $\begin{array}{l}\text { Ancylostoma } \\
\text { caninum }\end{array}$ & 51 & $\begin{array}{c}\mathrm{C} 1-\mathrm{C} 6, \mathrm{C} 2-\mathrm{C} 4 \\
\mathrm{C} 3-\mathrm{C} 5\end{array}$ & 266 nM (Chhabra et al., 2014) & NR \\
\hline Snake toxin BF9 & $\begin{array}{l}\text { Bungarus } \\
\text { fasciatus }\end{array}$ & 65 & $\begin{array}{c}\mathrm{C} 1-\mathrm{C} 6, \mathrm{C} 2-\mathrm{C} 4 \\
\mathrm{C} 3-\mathrm{C} 5\end{array}$ & 120 nM (Yang et al., 2014) & Perhaps ischemic stroke (Ding et al., 2018) \\
\hline
\end{tabular}

$I_{50}$, half maximal inhibitory concentration; $K_{d}$, dissociation constant; $N R$, not reported. 
A
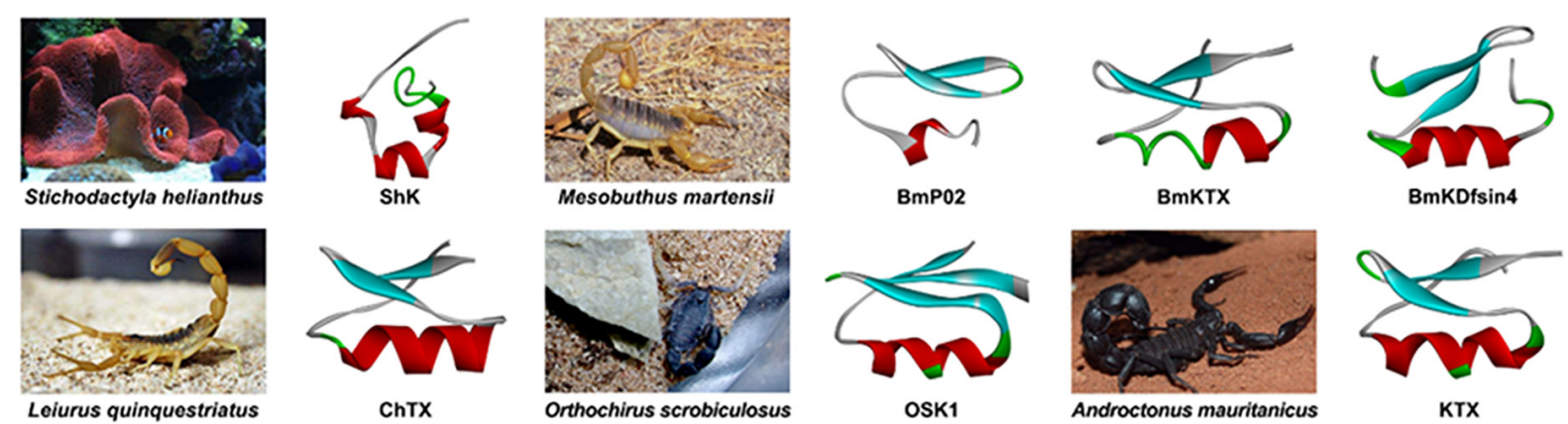

B

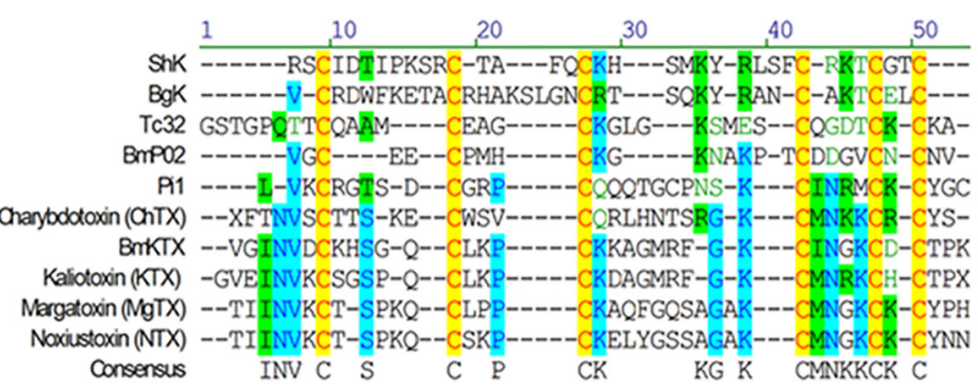

C

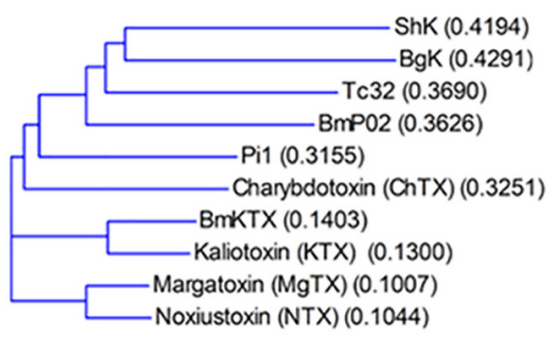

FIGURE 1 | The structures of Kv1.3 blocking toxin peptides. (A) The sea anemone toxin ShK (PDB: 1ROO) is isolated and purified from Sidirodromi hellinikou. The scorpion toxins BmP02 (PDB: 1DU9), BmKTX (PDB: 1BKT), and scorpion defensin BmKDfsin4 (using micasin as a template, PDB: 2LR5) are isolated and purified from Mesobuthus martensii. The scorpion toxin ChTX (PDB: 2CRD) is isolated and purified from Leiurus quinquestriatus. The scorpion toxin OSK1 (PDB: 1SCO) is isolated and purified from Orthochirus scrobiculosus. The scorpion toxin KTX (PDB: 2KTX) is isolated and purified from Androctonus mauritanicus. The three-dimensional structure data of the toxin polypeptide in the figure refers to the PDB. (B) Multiple sequence alignment of ShK and ShK-like Kv1.3 blockers from sea anemone or scorpion venom. Conserved cysteines formatting intrachain disulfide bonds are in red and shadowed in yellow; residues conserved in most of the peptides are shadowed in blue; residues with same charge in most of the peptides are shadowed in green. The species of toxins acting on Kv1.3 are mentioned above, except for Tc32 isolated from Tityus cambridgei; Pi1 isolated from Pandinus imperator; Kaliotoxin isolated from Androctonus mauritanicus; margatoxin isolated from Centruroides margaritatus; noxiustoxin isolated from Centruroides noxius. (C) A guide tree is constructed by ALIGNX, a component of the VECTOR NTI 11.0 software suite. Scores in the brackets are based on the identity of the amino acids chemical properties.

reveals that ShK has low homology with other $\mathrm{K}^{+}$channel blocking peptides, except for $\mathrm{BgK}$ from the sea anemone B. granulifera (Castaneda et al., 1995). The alanine-scanning experiment identifies that three residues, Ser-20, Lys-22, and Tyr23, are essential for ShK (Pennington et al., 1996) to bind $\mathrm{K}^{+}$ channels from rodent brain. Interestingly, these residues are also conserved in other Type 1 toxins. Especially, the dyad (Lys-Tyr) of the three residues is recently considered as the key player for binding potassium channels (Honma and Shiomi, 2006). In order to design the potential drugs targeting Kv1.3-related immune diseases with higher selectivity, the original toxin was engineered with chemical modification or site mutant genesis techniques. As a representative $\mathrm{K}^{+}$blocker, $\mathrm{ShK}$ has been receiving great attentions because of its higher affinity on Kv1.3 than other toxins previously described. At the same time, it exhibits effective blocking of other $\mathrm{Kv}$ channel isoforms in various important tissues with the affinity of pM concentration, such as Kv1.1 (cardiac), Kv1.4 (brain), and Kv1.6 (brain) (Beeton et al., 2011). Therefore, it is of importance to develop more selective analogs for Kv1.3 (Chi et al., 2012).

Due to the affinity of ShK for other Kv channel subtypes, the development of ShK analogs with higher selectivity for Kv1.3 has been promoted. The mimetic ShK-Dap22, in which Lys22 was replaced by a shorter, positively charged, non-natural amino acid diaminopropionic acid (Dap) (Middleton et al., 2003). Compared with ShK, it can inhibit Kv1.3 in sub-nanomolar concentration in vitro and has lower toxicity. ShK-170, it contains an L-phosphotyrosine attached via an aminoethyloxyethyloxyacetyl (Aeea) linker to the $\alpha$-amino group of Arg. To stabilize the C-terminus of ShK-170 replaced the C-terminal carboxyl with an amide to minimize digestion by carboxypeptidases. The novel analog ShK-186 retains the selectivity and potency profile of ShK-170 (Chi et al., 2012). ShK-186 which had a 100-fold improvement of selectivity for Kv1.3 over Kv1.1, and 1000-fold over Kv1.4 as well as Kv1.6 (Pennington et al., 2009). ShK-186 and its analogs had good therapeutic effects on animal models of human autoimmune diseases such as MS and rheumatoid arthritis (Beeton et al., 2001). Preclinical testing of ShK-186 show favorable results both in rats and monkeys (Tarcha et al., 2012). Unexpectedly, ShK-186 was found to have a long half-life through the sub-cutaneous injection, which revealed the sustained concentration at $\mathrm{pM}$ levels in plasma, resulting in a prolonged therapeutic efficacy (Tarcha et al., 2012). ShK-186 as a preclinical drug, which is also known as dalazatide, completed Phase $1 \mathrm{a}$ and $1 \mathrm{~b}$ trials in 2016. The Phase $1 \mathrm{~b}$ trial in mild-to-moderate plaque psoriasis patients 
showed that dalazatide was well tolerated and reduced psoriatic skin lesions (Tarcha et al., 2017). Up to now, dalazatide is being advanced as a treatment for various autoimmune diseases, including inclusion body myositis, lupus, ANCA vasculitis, MS, psoriasis, psoriatic arthritis, rheumatoid arthritis, Type 1 diabetes, and inflammatory bowel diseases (Chandy and Norton, 2017; Liao et al., 2019).

In addition, Kv1.3 could even be inhibited by scorpion toxins ranging from nanomolar to picomolar, including noxiustoxin (NTX) (Drakopoulou et al., 1995), charybdotoxin (ChTX) (Drakopoulou et al., 1995), margatoxin (MgTX), Orthochirus scrobiculosus toxin 1 (OSK1), kaliotoxin, agitoxin-2, hongotoxin, and anuroctoxin (Bhuyan and Seal, 2015; Schwartz et al., 2017). ChTX, a 37-residue polypeptide present in the venoms of the scorpion Leiurus quinquestriatus var. MgTx is a 39 amino acid peptide derived from Centruroides margaritatus with an $\mathrm{IC}_{50}$ of 11.7 pM against Kv1.3. HsTX1, from Heterometrus spinifer, is a 34-residue toxin peptide, C-terminally amidated peptide cross-linked by four disulfide bridges (Rashid et al., 2014). BmKTX, from Buthus martensii, was modified at three residues to create ADWX-1, which blocked Kv1.3 with 2 pM affinity (Han et al., 2008). OSK1 is a 38-residue toxin cross-linked by three disulfide bonds isolated from the venom of the Asian scorpion O. scrobiculosus. Bs6 toxin is a short-chain neurotoxin of 38 amino acid residues isolated from Buthus sindicus (Kohl et al., 2015). These toxins are typical Kv1.3 inhibitors and are also considered to have potential for the treatment of neuroinflammatory diseases (Table $\mathbf{1}$ and Figure $\mathbf{1}$ ).

We note that Kv1.3 plays a key role in physiological processes of $\mathrm{T}$ lymphocytes and microglial cells and is considered as a drug-target for neuroinflammatory diseases. Therefore, in this review, we also discuss the potential utility of ShK and other Kv1.3 blocking peptides in neuroinflammatory disorders therapy.

\section{SHK AND ITS ANALOGS AS A POTENTIAL THERAPEUTIC AGENT FOR NEUROINFLAMMATORY DISEASES}

\section{Multiple Sclerosis}

Multiple sclerosis, a demyelination disease of the central nervous system (CNS) which is caused by a variety of factors including autoimmunity, genetics, environmental factors, and individual susceptibility factors (Kaminska et al., 2017). The occurrence of MS is often accompanied by the destruction of the blood-brain barrier (BBB) and the infiltration of the CNS by reactive T-cell (Huang et al., 2017). Some studies have shown that the permeability of BBB is increased at the early stage of MS (Kirk et al., 2003; Ortiz et al., 2014). In animal model of experimental autoimmune encephalomyelitis (EAE), the results show that BBB tight junctions in vivo and in vitro were destroyed. It might be induced by the increase of inflammatory interleukin-17 (IL-17), which is produced from activated Th17 cells (Kebir et al., 2007; Peelen et al., 2011). In addition, astrocytes also play an important role in MS (Nair et al., 2008; Brosnan and Raine, 2013). Activated astrocytes increase BBB permeability and promote $\mathrm{T}$ cell entry into the CNS by withdrawing the foot around their blood vessels (Brosnan and Raine, 2013).

Based on the expression of the chemokine receptor CCR7 and phosphatase CD45RA, memory $\mathrm{T}$ lymphocytes can be divided into two subsets of central memory T cells (TCM) and effector memory T cells (TEM) (Pucca et al., 2016). TEM cells (CCR7-CD45RA-) rapidly enter the inflamed tissue, producing a large number of pro-inflammatory cytokines such as interferon$\gamma$ (IFN- $\gamma$ ) and IL-4, and exhibit immediate effector function. The Kv1.3 was first discovered in human $\mathrm{T}$ cells in 1984 (DeCoursey et al., 1984). Accumulated data for Kv1.3 showed higher expression levels in myelin-reactive $\mathrm{T}$ cells from the peripheral blood (PB) of MS patients compared to healthy controls (Wulff et al., 2003). Also in animal model of EAE, it has been confirmed that expression of Kv1.3 is significantly elevated (Rus et al., 2005) (Figure 2). These studies provide further rationale for the use of specific Kv1.3 antagonists in MS therapy.

Kv1.3 blocks membrane depolarization and maintains the driving force for $\mathrm{Ca}^{2+}$ entry by effluxing $\mathrm{K}^{+}$, which in turn participates in $\mathrm{T}$ cell activation, and $\mathrm{Ca}^{2+}$ activation signaling cascade, leading to $\mathrm{T}$ cell proliferation and cytokine production (Wulff et al., 2009; Bozic et al., 2018). These findings suggest Kv1.3 to be a valuable therapeutic target for immunosuppression in MS and EAE (Beeton et al., 2006; Wulff and Zhorov, 2008).

Kv1.3 channel blockers have been found to alleviate disease symptoms in animal autoimmune diseases, chronic inflammatory diseases, and metabolic disease models without obvious side effects (Perez-Verdaguer et al., 2016). More importantly, positive results have been shown in preclinical trials (Prentis et al., 2018), for example, improving the visual field and motor skills of most MS patients (Beeton and Chandy, 2005; Perez-Verdaguer et al., 2016). Therefore, Kv1.3 channel blockers have the potential to be developed as effective drugs for the treatment of MS and EAE (Rangaraju et al., 2009).

Blockers of Kv1.3 and other potassium channels have been found in the venom of numerous animals, including the venom of anemone (Wulff et al., 2019). In 1995, an effective $\mathrm{K}^{+}$channel blocker was extracted from the sea anemone (S. helianthus) by Castaneda et al. (1995) and then named it ShK (Wulff and Zhorov, 2008). ShK and derivatives reduce the inflammatory response of autoimmune diseases, by maintaining the integrity of BBB (Huang et al., 2017), reducing activation of TEM cells (Beeton et al., 2006), and eliminating respiratory bursts in activated microglia and subsequent secondary damage of neurons by microglia (Fordyce et al., 2005). Interestingly, experiments have demonstrated that this inhibition is achieved by effectively inhibiting the proliferation of TEM cells without affecting naive or TCM lymphocytes.

ShK-170 also plays an effective role in preventing active delayed type hypersensitivity (DTH) and acute adoptive EAE as well as in treating acute adoptive EAE in rats (Beeton et al., 2005). ShK-186 could inhibit DTH, TEM cell enlargement (Tarcha et al., 2012) and movement in inflamed tissues, but had no effect on lymph node homing or movement in naive and central memory T (TCM) cells (Matheu et al., 2008). ShK-186 can effectively improve the symptoms in a rat model of MS with good safety (Matheu et al., 2008). 


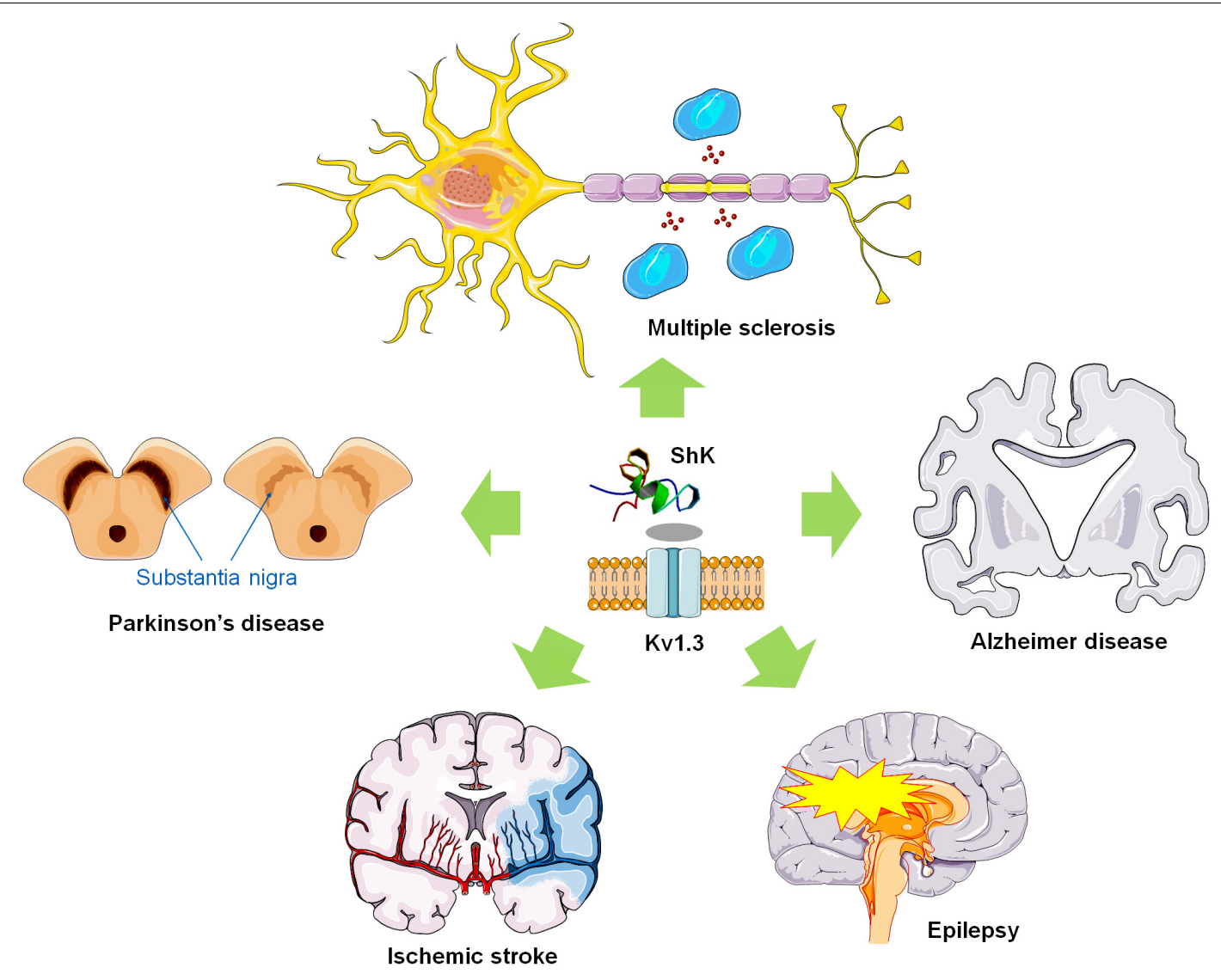

FIGURE 2 | ShK and Kv1.3 blocking polypeptides as potential therapeutic agents for neuroinflammatory diseases. ShK and Kv1.3 toxins might be used to treat multiple sclerosis, and other neuroinflammatory disorders via inhibiting Kv1.3 expressed in T lymphocytes as well as microglial cells.

In addition to ShK and its analogs, ChTX is specific to both KCa3.1 and Kv1.3 channels in human T lymphocytes, but the expression level of KCa3.1 in TEM is very low (Hu et al., 2007). Therefore, it is most likely to inhibit the proliferation of TEM cells by effectively blocking the Kv1.3 channel. ChTX might be a potential drug for MS. BmKTX-D33H inhibits cytokine production and proliferation in human $\mathrm{T}$ cells in vitro and significantly improves delayed hypersensitivity (DTH) response (Chen et al., 2018), highlighting its advantages as a potential drug for autoimmune diseases. Moreover, oligodendrocyte (OLG) causes axonal myelination of the CNS (Trapp et al., 1997) and the complement complex (C5b-9, composed of C5b, C6, C7, C8, and $\mathrm{C} 9$ proteins) is capable of inducing cell cycle activation in OLGs (Rus et al., 2006). Studies have found that complement activation and destruction of OLGs are among the most common pathological forms of MS (Cudrici et al., 2006). It is worth noting that Kv1.3 plays an important role in this process (Tegla et al., 2011). This explains the potential value of Kv1.3 blockers including rOsK-1 (Tegla et al., 2011) in the treatment of MS.

\section{Ischemic Stroke}

Stroke is an acute cerebrovascular disorder that causes brain tissue damage, which is the second leading disease causing sudden death after ischemic heart disease and accounts for $9 \%$ of deaths worldwide (Schmitz et al., 2005). Ischemic stroke is the most common type of stroke, usually occurring when the blood vessels in the neck or brain are blocked (Wallace et al., 2016). Formation of a clot in the blood vessels of the brain or neck, followed by its translocation to other part of the body, such as the heart, to the brain, which may cause severe narrowing of the arteries in the brain or to the brain, results in a stroke (van Os et al., 2016).

In the early stages of stroke, activated macrophages (M1) release a variety of cytokines (TNF- $\alpha$, IL-1- $\beta$, and IL-23), trigger neuronal damage, and induce TEM cell-mediated further inflammatory responses (Man et al., 2017). A few days later, macrophages could change to M2-like functions and begin to clear various inflammatory factors, cell debris, and secreted antiinflammatory as well as neurotrophic factors (IL-10, TGF- $\beta$, and IGF-1) to promote injury recovery (Man et al., 2017).

Similarly, microglia are highly malleable and can exhibit different phenotypes depending on different microenvironmental signals. Lipopolysaccharide (LPS) and IFN- $\gamma$ promote the differentiation of microglia into classical activated M1 type, along with producing high levels of pro-inflammatory cytokines, nitric oxide, and continuously impairing the CNS parenchyma (Huang et al., 2017), which contribute to the secondary expansion of the infarct (Chen et al., 2018). 
The voltage-gated potassium channel Kv1.3 plays important roles in microglia as well as macrophage activation by modulating $\mathrm{Ca}^{2+}$ signaling, oxidative burst, cytokine production, and neuronal killing (Kirk et al., 2003; Peelen et al., 2011; Ortiz et al., 2014), which is required for microglia or macrophage M1-like pro-inflammatory activation in vivo (Di Lucente et al., 2018) (Figure 2). Activated microglia in the pathology of ischemic stroke significantly contributes to secondary expansion of the infarct, and Kv1.3 blockers are thought to be useful in ameliorating this condition (Iadecola and Anrather, 2011; Macrez et al., 2011). Studies have shown that Kv1.3 inhibitors can retain beneficial "M2-like" functions while preferentially inhibiting "M1-like" inflammatory microglia/macrophage function (Murray et al., 2014). The most effective and specific small molecule, PAP-1 can inhibit Kv1.3 at an $\mathrm{IC}_{50}$ of $2 \mathrm{nmol} / \mathrm{L}$ (Schmitz et al., 2005), is orally available, brain penetrant, and does not have any long-term toxicity in rodents or primates (Azam et al., 2007; Pereira et al., 2007). It is worth noting that PAP-1 significantly reduces the levels of pro-inflammatory cytokines and infarct volume after ischemic injury and improves neurological deficits (Chen et al., 2018).

We speculate that other ShK derivatives are also likely to reduce pro-inflammatory factors and improve brain damage by inhibiting M1-like function of microglia or macrophages. It was reported that ShK-170, a compact derivative of ShK-186, has been shown to protect mice from microglia-mediated radiationinduced brain damage (Peng et al., 2014). Therefore, Kv1.3specific inhibitor ShK could be expected to be potential novel therapeutic agents for acute ischemic stroke. In addition to its significant role in immunity and inflammation, Kv1.3 has also found its potential role in the coagulation system (Ding et al., 2018). BF9 is a Kv1.3 blocker with anticoagulant activity (Ding et al., 2018) and provides a new molecular template for the discovery of lead drugs for immune and thromboticrelated human diseases.

\section{Alzheimer's Disease}

Alzheimer's disease $(\mathrm{AD})$ is a progressive neurodegenerative disorder of the brain, which is characterized by the structural and functional loss of neurons. The main pathogenesis now known has been described as progressive proliferation of plaques outside neurons (extracellular amyloid plaques) and neurofibrillary tangles inside neurons (hyperphosphorylated tau accumulation) (Takahashi et al., 2010; Selkoe and Hardy, 2016). However, a large number of amyloid reduction therapy (ART) clinical trials did not find the expected clinical improvement in $\mathrm{AD}$ patients. More and more attention has been paid to the neuroinflammation cascades mediated by primed microglia cells contributing to AD pathogenesis (Krause and Muller, 2010). Studies have shown that cytotoxic substances and proinflammatory cytokines, secreted by activated microglia, could induce nerve damage and aggravate the pathology of AD (Heneka et al., 2015). The modules underlying immune microglial cells or T lymphocytes as molecular systems were closely related to the pathophysiology of $\mathrm{AD}$, which were based on a networkbased analysis of whole-genome gene-expression profiling and genotypic data obtained from $1647 \mathrm{AD}$ as well as non-demented brain samples (Zhang et al., 2013). Neuroinflammation cascades mediated by activated microglial cells and $\mathrm{T}$ lymphocytes contribute to AD pathogenesis (Janke and Yong, 2006; Zheng et al., 2008). Thus, it is concluded that immune-associated alterations significantly contribute to the pathophysiology of $\mathrm{AD}$, even though an effective therapeutic target is not yet available in clinic.

In addition to being a drug target for arrhythmias and Type 2 diabetes, $\mathrm{K}^{+}$channels have also been proposed as targets for the treatment of immunosuppression, cancer, and various neurological disorders. Including the abnormal expression of $\mathrm{K}^{+}$ channel has been detected in brains of AD patients (Poulopoulou et al., 2010). Furthermore, the ShK-sensitive Kv1.3 channel is mainly expressed in T lymphocytes, macrophages, and microglia, and the up-regulated expression of Kv1.3 channels in human $\mathrm{T}$ and $\mathrm{B}$ lymphocytes was closely related to the occurrence and development of autoimmune diseases (Jang et al., 2015; Kazama, 2015). Microglia represent innate immune cells in $\mathrm{AD}$ that mediate neuroinflammation, and voltage-gated Kv1.3 potassium channels are key regulators of microglial function. Previous study has showed that Kv1.3 plays an important role in immune cell activation by modulating $\mathrm{Ca}^{2+}$ signaling (Feske et al., 2015) (Figure 2) and in the AD model through the high expression of pro-inflammatory microglia (Maezawa et al., 2018). Moreover, the expression of Kv1.3 is increased in human $\mathrm{AD}$ brains and the elevation is limited to microglial cells. Kv1.3 blockers have further been demonstrated to inhibit the activation of microglia, which could mediate neurotoxicity in cell culture (Fordyce et al., 2005). These findings suggest that Kv1.3 might be a pathologically relevant microglial target in AD (Rangaraju et al., 2015). Similarity, the Kv1.3 channel was also found to be expressed in T lymphocytes (Chandy et al., 1984; DeCoursey et al., 1984). With continued investigation in $\mathrm{AD}$ patients, high expression levels of Kv1.3 channels were successively confirmed in activated T cell (Beeton et al., 2006). Kv1.3 channel blockers were able to inhibit TEM cell activation and suppress the secretion of related cytokines (such as IL-2, IL4, IFN- $\gamma$, and TNF- $\alpha$ ) (Beeton et al., 2006; Nicolaou et al., 2007). In summary, the microglial and lymphocytic Kv1.3 channels are becoming an attractive target for the research and generation of drugs against $\mathrm{ADs}$.

At present, the number of in vivo diagnostic techniques available for detection of AD is very limited. Several drugs for treating symptoms of $\mathrm{AD}$ do not alter disease progression and their benefits are at most modest, which indicates an urgent need for novel target discovery. As mentioned above, the expression of Kv1.3 is increased in $\mathrm{AD}$ brains and blocking its expression might be beneficial for AD patients. Pro-inflammatory diseaseassociated microglia (DAM) emerged early in the AD mouse model and was characterized by a pro-inflammatory gene (Il12b, Ilb), with surface marker CD44, potassium channel Kv1.3, and regulatory factors. It was reported that the ShK223 peptide promotes anti-inflammatory DAM by agonizing $\mathrm{LXR} \alpha / \beta$ and blocking Kv1.3, inhibits pro-inflammatory DAM, and increases $\mathrm{A} \beta$ clearance in the $\mathrm{AD}$ model (Rangaraju et al., 2018). Subsequently, Norton and Chandy (2017) investigated the effects of BmKTX (ADWX-1), OsK1-K16-D20, and 
HsTx1 [R14A] targeting Kv1.3 in the treatment of $\mathrm{AD}$ (Norton and Chandy, 2017).

Studies showed that PAP-1, as a small molecule Kv1.3 blocker, could reduce neuroinflammation, decrease cerebral amyloid load, enhance hippocampal neuronal plasticity, and improve behavioral deficits in APP/PS1 transgenic mice (Maezawa et al., 2018). Thus, we infer that using Kv1.3specific blockers as attractive therapeutic agents to mitigate $\mathrm{A} \beta$-induced pro-inflammatory microglia, which are highly relevant to AD pathogenesis. Therefore, ShK and its analogs, which were the specific blockers of Kv1.3, are capable to be the candidate drugs for $\mathrm{AD}$.

\section{Other Pathologies}

The activation of voltage-gated potassium channels after the action potential is the main regulatory effect that determines the degree of repolarization and repeated neuronal discharge. Epilepsy is a chronic disease of transient brain dysfunction caused by sudden abnormal discharge of brain neurons (Wittner et al., 2001; Manford, 2017). Potassium channels play an important role in maintaining resting membrane potential and regulating cell excitability of neurons, which can cause neuropathic pain or neurological diseases (such as epilepsy and ataxia) (Wickenden, 2002; Pimentel et al., 2008). In the Kv channel, the Kv1 subfamily leads to differences in susceptibility to epilepsy in the brain (Pena and Coimbra, 2015). In fact, many of the symptoms of hyperexcitability, including epilepsy, are caused by mutations or downregulation of the Kv1 channel (Glasscock, 2019; Verdura et al., 2019). Studies have shown that the convulsive agent pentylenetetrazol can significantly reduce the Kv1.3 currents (Madeja et al., 1997), indicating that Kv1.3 may be associated with epileptogenesis (Figure 2). Activation of microglia and neuroinflammation are important markers of epileptogenesis (Eyo et al., 2017). The activation of microglia and the expression of inflammatory factors were also positively correlated with the progression of epilepsy in the hippocampus of patients with epilepsy (Hiragi et al., 2018). Early studies have shown that pro-inflammatory substances induce the increase of potassium currents in microglia (Fordyce et al., 2005). The presence of Kv1.3 in microglia regulates the proliferation of glial cells, with causing potassium efflux (Fordyce et al., 2005; Peng et al., 2014). The above data indicate that abnormal expression of Kv1.3 is closely related to the occurrence and development of epilepsy.

Parkinson's disease (PD) is a degenerative disease of the CNS, which involves motor deficits including tremors, muscle rigidity, bradykinesia, and impaired gait (Sampson et al., 2016). Tubert et al. (2016) showed that Kv1.3-mediated currents in PD striatum significantly reduced the inhibition of cholinergic interneuron excitability. Early studies have found that microglia are activated in the early stages of PD patients and throughout the disease process (Sanchez-Guajardo et al., 2015). The upregulation of $\mathrm{K}^{+}$channels is considered as a hallmark of microglial activation (Rangaraju et al., 2015). Upon this activation, there is an increased expression of $\mathrm{Kv}$ channels (Di Lucente et al., 2018), mainly Kv1.5 and Kv1.3 channels. Among them, Kv1.3 currents become predominant upon proliferation of microglial cells (Kotecha and Schlichter, 1999). Accumulated data indicate that Kv1.3 channels maybe as potential targets for PD therapy (Figure 2).

The above fact suggests that $\mathrm{ShK}$, as an effective regulator of microglia and T lymphocyte activation (Castaneda et al., 1995), and Kv1.3 blockers, has a high pharmacological value for the development of a more stable and highly selective ShK. They constitute a large pharmacological armamentarium to target Kv1.3 channels with high potency and specificity (Wulff and Zhorov, 2008), which could offer treatments targeting epilepsy and PD. In addition, MgTx (Bartok et al., 2014), AgTx-2 (Pimentel et al., 2008), OsK-1 (Mouhat et al., 2005), and BF9 (Chen et al., 2001) depend on their functional characteristics that can effectively inhibit Kv1.3, which have medical values on the further pharmacological studies.

\section{PROSPECT AND CONCLUSION}

Up to now, there are 15 venom-derived drugs that used to treat a variety of diseases, including hypertension, pain, and diabetes, in clinic. As a result, many lives have been saved. Moreover, 13 animal-derived toxins are considered to be drug candidates, having been entering in clinical trials (King, 2011). Among them, ShK derivatives, ShK-186 and ShK-192, mainly used to treat autoimmune diseases, including neuroinflammatory MS by targeting Kv1.3 channels. In this review, we discuss the possibility of ShK for clinical treatment on other Kv1.3 relevant neuroinflammatory diseases. It is shown that ShK could effectively suppress the activation of microglial cells as well as $\mathrm{T}$ lymphocytes in stroke, epilepsy, $\mathrm{AD}$, and $\mathrm{PD}$. In vivo studies also demonstrated that inhibition of Kv1.3 is favorable for the reversion of neuroinflammatory diseases. This brings the dawn of effective control of diseases such as $\mathrm{AD}$ and PD that are suspected to be overcome. However, it is still a challenge for ShK used to the treatment of neuroinflammatory diseases. The first problem underlying the application of these peptides is that they couldn't be taken orally, mainly because they are difficult to penetrate the intestinal mucosa. Due to the molecular size, polarity, hydrophilicity, and chargeability, the cell membrane penetration of ShK is hampered. The second obstacle is that ShK cannot cross the BBB. Different from MS, the myelin and BBB are not destroyed in other neuroinflammatory diseases (Li et al., 2015). Clinical application of ShK for treating neuroinflammatory diseases will encounter difficulties. Fortunately, the situation is not unsolvable, we still have a glimmer of light. A few years ago, scientists at the Sunnybrook Health Science Center in Canada used focused ultrasound technology to successfully pass chemotherapy drugs across the BBB in a non-invasive manner (Burgess et al., 2015) and reach the location of the tumor, which is of great significance in the field of neuropharmacology. In addition, the cell penetrating peptide (CPP) (Kristensen et al., 2016) with a strong cell membrane penetration could be used as a drug carrier to assist the passage of polypeptide drugs across the cell membrane ( $\mathrm{Li}$ et al., 2015). The fusion protein consists of CPP and ShK might be developed as an oral drug for neuroinflammatory diseases. In short, finding a suitable, safe, and efficient way to promote the clinical use of ShK is the most valuable points to be solved. 


\section{AUTHOR CONTRIBUTIONS}

$\mathrm{XW}, \mathrm{GL}, \mathrm{ZZ}, \mathrm{SZ}, \mathrm{YZ}, \mathrm{YJ}$, and JT drafted the manuscript and revised it critically for intellectual content. JG, LY, and JC drawn the figures. All authors read and approved the final version of the manuscript before submission.

\section{FUNDING}

This work was supported by the National Science Foundation of China (Nos. 81603410, 81903995, and 31771191), the Shanghai Municipal Commission of Health and

\section{REFERENCES}

Anderluh, G., and Macek, P. (2002). Cytolytic peptide and protein toxins from sea anemones (Anthozoa: Actiniaria). Toxicon 40, 111-124. doi: 10.1016/s00410101(01)00191-x

Aneiros, A., Garcia, I., Martinez, J. R., Harvey, A. L., Anderson, A. J., Marshall, D. L., et al. (1993). A potassium channel toxin from the secretion of the sea anemone Bunodosoma granulifera. Isolation, amino acid sequence and biological activity. Biochim. Biophys. Acta 1157, 86-92. doi: 10.1016/03044165(93)90082-j

Azam, P., Sankaranarayanan, A., Homerick, D., Griffey, S., and Wulff, H. (2007). Targeting effector memory T cells with the small molecule Kv1.3 blocker PAP1 suppresses allergic contact dermatitis. J. Invest. Dermatol. 127, 1419-1429. doi: $10.1038 /$ sj.jid.5700717

Bartok, A., Toth, A., Somodi, S., Szanto, T. G., Hajdu, P., Panyi, G., et al. (2014). Margatoxin is a non-selective inhibitor of human Kv1.3 K+ channels. Toxicon 87, 6-16. doi: 10.1016/j.toxicon.2014.05.002

Beeton, C., and Chandy, K. G. (2005). Potassium channels, memory T cells, and multiple sclerosis. Neuroscientist 11, 550-562. doi: 10.1177/1073858405278016

Beeton, C., Pennington, M. W., and Norton, R. S. (2011). Analogs of the sea anemone potassium channel blocker ShK for the treatment of autoimmune diseases. Inflamm. Allergy Drug Targets 10, 313-321. doi: 10.2174/ 187152811797200641

Beeton, C., Pennington, M. W., Wulff, H., Singh, S., Nugent, D., Crossley, G., et al. (2005). Targeting effector memory $\mathrm{T}$ cells with a selective peptide inhibitor of Kv1.3 channels for therapy of autoimmune diseases. Mol. Pharmacol. 67, 1369-1381. doi: 10.1124/mol.104.008193

Beeton, C., Wulff, H., Barbaria, J., Clot-Faybesse, O., Pennington, M., Bernard, D., et al. (2001). Selective blockade of T lymphocyte $\mathrm{K}(+)$ channels ameliorates experimental autoimmune encephalomyelitis, a model for multiple sclerosis. Proc. Natl. Acad. Sci. U.S.A. 98, 13942-13947. doi: 10.1073/pnas.24149 7298

Beeton, C., Wulff, H., Standifer, N. E., Azam, P., Mullen, K. M., Pennington, M. W., et al. (2006). Kv1.3 channels are a therapeutic target for T cell-mediated autoimmune diseases. Proc. Natl. Acad. Sci. U.S.A. 103, 17414-17419. doi: 10. 1073/pnas.0605136103

Beraud, E., Viola, A., Regaya, I., Confort-Gouny, S., Siaud, P., Ibarrola, D., et al. (2006). Block of neural Kv1.1 potassium channels for neuroinflammatory disease therapy. Ann. Neurol. 60, 586-596. doi: 10.1002/ana.21007

Bhuyan, R., and Seal, A. (2015). Molecular dynamics of Kv1.3 ion channel and structural basis of its inhibition by scorpion toxin-OSK1 derivatives. Biophys. Chem. 203-204, 1-11. doi: 10.1016/j.bpc.2015.04.004

Bozic, I., Tesovic, K., Laketa, D., Adzic, M., Jakovljevic, M., Bjelobaba, I., et al. (2018). Voltage gated potassium channel Kv1.3 is upregulated on activated astrocytes in experimental autoimmune encephalomyelitis. Neurochem. Res. 43, 1020-1034. doi: 10.1007/s11064-018-2509-8

Brosnan, C. F., and Raine, C. S. (2013). The astrocyte in multiple sclerosis revisited. Glia 61, 453-465. doi: 10.1002/glia.22443
Family Planning Fund (Nos. 20184Y0086, 2016JP007, and 2018JQ003), Project for Capacity Promotion of Putuo District Clinical Special Disease, Project within budget of Shanghai University of Traditional Chinese Medicine (No. 18TS086), the Key Speciality Program (No. 2016102A) and the Research Project (Nos. 2016208A and 2018313) of Putuo Hospital, Shanghai University of Traditional Chinese Medicine, Science and Technology Innovation Project of Putuo District Health System (Nos. ptkwws201902 and ptkwws201908), the Natural Science Foundation of Shanghai (No. 19ZR1447900), and Youth Talent Promotion Project of China Association of Chinese Medicine (No. 2019-QNRC2C10 to JT).

Burgess, A., Shah, K., Hough, O., and Hynynen, K. (2015). Focused ultrasoundmediated drug delivery through the blood-brain barrier. Expert Rev. Neurother. 15, 477-491. doi: 10.1586/14737175.2015.1028369

Castaneda, O., Sotolongo, V., Amor, A. M., Stocklin, R., Anderson, A. J., Harvey, A. L., et al. (1995). Characterization of a potassium channel toxin from the Caribbean Sea anemone Stichodactyla helianthus. Toxicon 33, 603-613. doi: 10.1016/0041-0101(95)00013-c

Chandy, K. G., Decoursey, T. E., Cahalan, M. D., Mclaughlin, C., and Gupta, S. (1984). Voltage-gated potassium channels are required for human $\mathrm{T}$ lymphocyte activation. J. Exp. Med. 160, 369-385. doi: 10.1084/jem.160.2.369

Chandy, K. G., and Norton, R. S. (2017). Peptide blockers of Kv1.3 channels in $\mathrm{T}$ cells as therapeutics for autoimmune disease. Curr. Opin. Chem. Biol. 38, 97-107. doi: 10.1016/j.cbpa.2017.02.015

Chen, C., Hsu, C. H., Su, N. Y., Lin, Y. C., Chiou, S. H., and Wu, S. H. (2001). Solution structure of a Kunitz-type chymotrypsin inhibitor isolated from the elapid snake Bungarus fasciatus. J. Biol. Chem. 276, 45079-45087. doi: 10.1074/ jbc.M106182200

Chen, Y. J., Nguyen, H. M., Maezawa, I., Jin, L. W., and Wulff, H. (2018). Inhibition of the potassium channel Kv1.3 reduces infarction and inflammation in ischemic stroke. Ann. Clin. Transl. Neurol. 5, 147-161. doi: 10.1002/acn3.513

Chhabra, S., Chang, S. C., Nguyen, H. M., Huq, R., Tanner, M. R., Londono, L. M., et al. (2014). Kv1.3 channel-blocking immunomodulatory peptides from parasitic worms: implications for autoimmune diseases. FASEB J. 28, 39523964. doi: 10.1096/fj.14-251967

Chi, V., Pennington, M. W., Norton, R. S., Tarcha, E. J., Londono, L. M., Sims-Fahey, B., et al. (2012). Development of a sea anemone toxin as an immunomodulator for therapy of autoimmune diseases. Toxicon 59, 529-546. doi: 10.1016/j.toxicon.2011.07.016

Chiang, E. Y., Li, T., Jeet, S., Peng, I., Zhang, J., Lee, W. P., et al. (2017). Potassium channels Kv1.3 and KCa3.1 cooperatively and compensatorily regulate antigenspecific memory $\mathrm{T}$ cell functions. Nat. Commun. 8:14644. doi: 10.1038/ ncomms 14644

Cotton, J., Crest, M., Bouet, F., Alessandri, N., Gola, M., Forest, E., et al. (1997). A potassium-channel toxin from the sea anemone Bunodosoma granulifera, an inhibitor for Kv1 channels. Revision of the amino acid sequence, disulfidebridge assignment, chemical synthesis, and biological activity. Eur. J. Biochem. 244, 192-202. doi: 10.1111/j.1432-1033.1997.00192.x

Cudrici, C., Niculescu, T., Niculescu, F., Shin, M. L., and Rus, H. (2006). Oligodendrocyte cell death in pathogenesis of multiple sclerosis: protection of oligodendrocytes from apoptosis by complement. J. Rehabil. Res. Dev. 43, 123-132. doi: 10.1682/jrrd.2004.08.0111

DeCoursey, T. E., Chandy, K. G., Gupta, S., and Cahalan, M. D. (1984). Voltagegated $\mathrm{K}+$ channels in human T lymphocytes: a role in mitogenesis? Nature 307, 465-468. doi: 10.1038/307465a0

Devaux, J., Beeton, C., Beraud, E., and Crest, M. (2004). [Ion channels and demyelination: basis of a treatment of experimental autoimmune encephalomyelitis (EAE) by potassium channel blockers]. Rev. Neurol. 160, S16-S27. 
Di Lucente, J., Nguyen, H. M., Wulff, H., Jin, L. W., and Maezawa, I. (2018). The voltage-gated potassium channel Kv1.3 is required for microglial proinflammatory activation in vivo. Glia 66, 1881-1895. doi: 10.1002/glia.23457

Ding, L., Hao, J., Luo, X., Zhu, W., Wu, Z., Qian, Y., et al. (2018). The Kv1.3 channel-inhibitory toxin BF9 also displays anticoagulant activity via inhibition of factor XIa. Toxicon 152, 9-15. doi: 10.1016/j.toxicon.2018.07.014

Diochot, S., Loret, E., Bruhn, T., Beress, L., and Lazdunski, M. (2003). APETx1, a new toxin from the sea anemone Anthopleura elegantissima, blocks voltagegated human ether-a-go-go-related gene potassium channels. Mol. Pharmacol. 64, 59-69. doi: 10.1124/mol.64.1.59

Diochot, S., Schweitz, H., Beress, L., and Lazdunski, M. (1998). Sea anemone peptides with a specific blocking activity against the fast inactivating potassium channel Kv3.4. J. Biol. Chem. 273, 6744-6749. doi: 10.1074/jbc.273. 12.6744

Drakopoulou, E., Cotton, J., Virelizier, H., Bernardi, E., Schoofs, A. R., Partiseti, M., et al. (1995). Chemical synthesis, structural and functional characterisation of noxiustoxin, a powerful blocker of lymphocyte voltage-dependent $\mathrm{K}+$ channels. Biochem. Biophys. Res. Commun. 213, 901-907. doi: 10.1006/bbrc.1995.2214

Eyo, U. B., Murugan, M., and Wu, L. J. (2017). Microglia-neuron communication in epilepsy. Glia 65, 5-18. doi: 10.1002/glia.23006

Feske, S., Wulff, H., and Skolnik, E. Y. (2015). Ion channels in innate and adaptive immunity. Annu. Rev. Immunol. 33, 291-353. doi: 10.1146/annurev-immunol032414-112212

Fordyce, C. B., Jagasia, R., Zhu, X., and Schlichter, L. C. (2005). Microglia Kv1.3 channels contribute to their ability to kill neurons. J. Neurosci. 25, 7139-7149. doi: 10.1523/jneurosci.1251-05.2005

Gairi, M., Romi, R., Fernandez, I., Rochat, H., Martin-Eauclaire, M. F., Van Rietschoten, J., et al. (1997). 3D structure of kaliotoxin: is residue 34 a key for channel selectivity? J. Pept. Sci. 3, 314-319.

Gendeh, G. S., Young, L. C., De Medeiros, C. L., Jeyaseelan, K., Harvey, A. L., and Chung, M. C. (1997). A new potassium channel toxin from the sea anemone Heteractis magnifica: isolation, cDNA cloning, and functional expression. Biochemistry 36, 11461-11471. doi: 10.1021/bi970253d

Gimenez-Gallego, G., Navia, M. A., Reuben, J. P., Katz, G. M., Kaczorowski, G. J., and Garcia, M. L. (1988). Purification, sequence, and model structure of charybdotoxin, a potent selective inhibitor of calcium-activated potassium channels. Proc. Natl. Acad. Sci. U.S.A. 85, 3329-3333. doi: 10.1073/pnas.85.10. 3329

Glasscock, E. (2019). Kv1.1 channel subunits in the control of neurocardiac function. Channels 13, 299-307. doi: 10.1080/19336950.2019.1635864

Gurrola, G. B., Hernandez-Lopez, R. A., Rodriguez De La Vega, R. C., Varga, Z., Batista, C. V., Salas-Castillo, S. P., et al. (2012). Structure, function, and chemical synthesis of Vaejovis mexicanus peptide 24: a novel potent blocker of Kv1.3 potassium channels of human T lymphocytes. Biochemistry 51, 40494061. doi: 10.1021/bi300060n

Han, S., Yi, H., Yin, S. J., Chen, Z. Y., Liu, H., Cao, Z. J., et al. (2008). Structural basis of a potent peptide inhibitor designed for Kv1.3 channel, a therapeutic target of autoimmune disease. J. Biol. Chem. 283, 19058-19065. doi: 10.1074/ jbc.M802054200

Heneka, M. T., Carson, M. J., El Khoury, J., Landreth, G. E., Brosseron, F., Feinstein, D. L., et al. (2015). Neuroinflammation in Alzheimer's disease. Lancet Neurol. 14, 388-405. doi: 10.1016/s1474-4422(15)70016-5

Hiragi, T., Ikegaya, Y., and Koyama, R. (2018). Microglia after seizures and in epilepsy. Cells 7:E26. doi: 10.3390/cells7040026

Honma, T., and Shiomi, K. (2006). Peptide toxins in sea anemones: structural and functional aspects. Mar. Biotechnol. 8, 1-10. doi: 10.1007/s10126-005-5093-2

Hu, L., Pennington, M., Jiang, Q., Whartenby, K. A., and Calabresi, P. A. (2007). Characterization of the functional properties of the voltage-gated potassium channel Kv1.3 in human CD4+ T lymphocytes. J. Immunol. 179, 4563-4570. doi: 10.4049/jimmunol.179.7.4563

Huang, J., Han, S., Sun, Q., Zhao, Y., Liu, J., Yuan, X., et al. (2017). Kv1.3 channel blocker (ImKTx88) maintains blood-brain barrier in experimental autoimmune encephalomyelitis. Cell Biosci. 7:31. doi: 10.1186/s13578-0170158-2

Iadecola, C., and Anrather, J. (2011). The immunology of stroke: from mechanisms to translation. Nat. Med. 17, 796-808. doi: 10.1038/nm.2399

Jang, S. H., Byun, J. K., Jeon, W. I., Choi, S. Y., Park, J., Lee, B. H., et al. (2015). Nuclear localization and functional characteristics of voltage-gated potassium channel Kv1.3. J. Biol. Chem. 290, 12547-12557. doi: 10.1074/jbc.M114. 561324

Janke, A. D., and Yong, V. W. (2006). Impact of IVIg on the interaction between activated T cells and microglia. Neurol. Res. 28, 270-274. doi: 10.1179/ $016164106 \times 98143$

Jensen, B. S., Hertz, M., Christophersen, P., and Madsen, L. S. (2002). The Ca2+activated $\mathrm{K}+$ channel of intermediate conductance:a possible target for immune suppression. Expert Opin. Ther. Targets 6, 623-636. doi: 10.1517/14728222.6. 6.623

Kaminska, J., Koper, O. M., Piechal, K., and Kemona, H. (2017). Multiple sclerosis - etiology and diagnostic potential. Postepy Hig. Med. Dosw. 71, 551-563. doi: 10.5604/01.3001.0010.3836

Kazama, I. (2015). Physiological significance of delayed rectifier K(+) channels (Kv1.3) expressed in $\mathrm{T}$ lymphocytes and their pathological significance in chronic kidney disease. J. Physiol. Sci. 65, 25-35. doi: 10.1007/s12576-0140331-x

Kebir, H., Kreymborg, K., Ifergan, I., Dodelet-Devillers, A., Cayrol, R., Bernard, M., et al. (2007). Human TH17 lymphocytes promote blood-brain barrier disruption and central nervous system inflammation. Nat. Med. 13, 1173-1175. doi: $10.1038 / \mathrm{nm} 1651$

Kharrat, R., Mansuelle, P., Sampieri, F., Crest, M., Oughideni, R., Van Rietschoten, J., et al. (1997). Maurotoxin, a four disulfide bridge toxin from Scorpio maurus venom: purification, structure and action on potassium channels. FEBS Lett. 406, 284-290. doi: 10.1016/s0014-5793(97)00285-8

King, G. F. (2011). Venoms as a platform for human drugs: translating toxins into therapeutics. Expert Opin. Biol. Ther. 11, 1469-1484. doi: 10.1517/14712598. 2011.621940

Kirk, J., Plumb, J., Mirakhur, M., and Mcquaid, S. (2003). Tight junctional abnormality in multiple sclerosis white matter affects all calibres of vessel and is associated with blood-brain barrier leakage and active demyelination. J. Pathol. 201, 319-327. doi: 10.1002/path.1434

Kohl, B., Rothenberg, I., Ali, S. A., Alam, M., Seebohm, G., Kalbacher, H., et al. (2015). Solid phase synthesis, NMR structure determination of alpha-KTx3.8, its in silico docking to Kv1.x potassium channels, and electrophysiological analysis provide insights into toxin-channel selectivity. Toxicon 101, 70-78. doi: 10.1016/j.toxicon.2015.04.018

Kotecha, S. A., and Schlichter, L. C. (1999). A Kv1.5 to Kv1.3 switch in endogenous hippocampal microglia and a role in proliferation. J. Neurosci. 19, 10680-10693. doi: 10.1523/jneurosci.19-24-10680.1999

Krause, D. L., and Muller, N. (2010). Neuroinflammation, microglia and implications for anti-inflammatory treatment in Alzheimer's disease. Int. J. Alzheimers Dis. 2010:732806. doi: 10.4061/2010/732806

Kristensen, M., Birch, D., and Morck Nielsen, H. (2016). Applications and challenges for use of cell-penetrating peptides as delivery vectors for peptide and protein cargos. Int. J. Mol. Sci. 17:E185. doi: 10.3390/ijms17020185

Li, S., Hou, H., Mori, T., Sawmiller, D., Smith, A., Tian, J., et al. (2015). Swedish mutant APP-based BACE1 binding site peptide reduces APP beta-cleavage and cerebral Abeta levels in Alzheimer's mice. Sci. Rep. 5:11322. doi: 10.1038/ srep11322

Liao, Q., Feng, Y., Yang, B., and Lee, S. M. (2019). Cnidarian peptide neurotoxins: a new source of various ion channel modulators or blockers against central nervous systems disease. Drug Discov. Today 24, 189-197. doi: 10.1016/j.drudis. 2018.08.011

Macrez, R., Ali, C., Toutirais, O., Le Mauff, B., Defer, G., Dirnagl, U., et al. (2011). Stroke and the immune system: from pathophysiology to new therapeutic strategies. Lancet Neurol. 10, 471-480. doi: 10.1016/s1474-4422(11)7 0066-7

Madeja, M., Musshoff, U., and Speckmann, E. J. (1997). Diversity of potassium channels contributing to differences in brain area-specific seizure susceptibility: sensitivity of different potassium channels to the epileptogenic agent pentylenetetrazol. Eur. J. Neurosci. 9, 390-395. doi: 10.1111/j.1460-9568.1997. tb01408.x

Madio, B., King, G. F., and Undheim, E. A. B. (2019). Sea anemone toxins: a structural overview. Mar Drugs 17, E325. doi: 10.3390/md17060325

Maezawa, I., Nguyen, H. M., Di Lucente, J., Jenkins, D. P., Singh, V., Hilt, S., et al. (2018). Kv1.3 inhibition as a potential microglia-targeted therapy for Alzheimer's disease: preclinical proof of concept. Brain 141, 596-612. doi: 10. 1093/brain/awx346 
Man, S. M., Karki, R., and Kanneganti, T. D. (2017). Molecular mechanisms and functions of pyroptosis, inflammatory caspases and inflammasomes in infectious diseases. Immunol. Rev. 277, 61-75. doi: 10.1111/imr.12534

Manford, M. (2017). Recent advances in epilepsy. J. Neurol. 264, 1811-1824. doi: 10.1007/s00415-017-8394-2

Matheu, M. P., Beeton, C., Garcia, A., Chi, V., Rangaraju, S., Safrina, O., et al. (2008). Imaging of effector memory $\mathrm{T}$ cells during a delayed-type hypersensitivity reaction and suppression by Kv1.3 channel block. Immunity 29, 602-614. doi: 10.1016/j.immuni.2008.07.015

Meng, L., Xie, Z., Zhang, Q., Li, Y., Yang, F., Chen, Z., et al. (2016). Scorpion potassium channel-blocking defensin highlights a functional link with neurotoxin. J. Biol. Chem. 291, 7097-7106. doi: 10.1074/jbc.M115. 680611

Middleton, R. E., Sanchez, M., Linde, A. R., Bugianesi, R. M., Dai, G., Felix, J. P., et al. (2003). Substitution of a single residue in Stichodactyla helianthus peptide, ShK-Dap22, reveals a novel pharmacological profile. Biochemistry 42, 13698-13707. doi: 10.1021/bi035209e

Minagawa, S., Ishida, M., Nagashima, Y., and Shiomi, K. (1998). Primary structure of a potassium channel toxin from the sea anemone Actinia equina. FEBS Lett. 427, 149-151. doi: 10.1016/s0014-5793(98)00403-7

Mouhat, S., Visan, V., Ananthakrishnan, S., Wulff, H., Andreotti, N., Grissmer, S., et al. (2005). K+ channel types targeted by synthetic OSK1, a toxin from Orthochirus scrobiculosus scorpion venom. Biochem. J. 385, 95-104. doi: 10. 1042/BJ20041379

Murray, P. J., Allen, J. E., Biswas, S. K., Fisher, E. A., Gilroy, D. W., Goerdt, S., et al. (2014). Macrophage activation and polarization: nomenclature and experimental guidelines. Immunity 41, 14-20. doi: 10.1016/j.immuni.2014. 06.008

Nair, A., Frederick, T. J., and Miller, S. D. (2008). Astrocytes in multiple sclerosis: a product of their environment. Cell Mol. Life Sci. 65, 2702-2720. doi: 10.1007/ s00018-008-8059-5

Nicolaou, S. A., Szigligeti, P., Neumeier, L., Lee, S. M., Duncan, H. J., Kant, S. K., et al. (2007). Altered dynamics of Kv1.3 channel compartmentalization in the immunological synapse in systemic lupus erythematosus. J. Immunol. 179, 346-356. doi: 10.4049/jimmunol.179.1.346

Norton, R. S. (1991). Structure and structure-function relationships of sea anemone proteins that interact with the sodium channel. Toxicon 29, 1051-1084. doi: 10.1016/0041-0101(91)90205-6

Norton, R. S., and Chandy, K. G. (2017). Venom-derived peptide inhibitors of voltage-gated potassium channels. Neuropharmacology 127, 124-138. doi: 10. 1016/j.neuropharm.2017.07.002

Ortiz, G. G., Pacheco-Moises, F. P., Macias-Islas, M. A., Flores-Alvarado, L. J., Mireles-Ramirez, M. A., Gonzalez-Renovato, E. D., et al. (2014). Role of the blood-brain barrier in multiple sclerosis. Arch. Med. Res. 45, 687-697. doi: 10.1016/j.arcmed.2014.11.013

Peelen, E., Damoiseaux, J., Smolders, J., Knippenberg, S., Menheere, P., Tervaert, J. W., et al. (2011). Th17 expansion in MS patients is counterbalanced by an expanded CD39+ regulatory $\mathrm{T}$ cell population during remission but not during relapse. J. Neuroimmunol. 240-241, 97-103. doi: 10.1016/j.jneuroim.2011. 09.013

Pena, S. D., and Coimbra, R. L. (2015). Ataxia and myoclonic epilepsy due to a heterozygous new mutation in KCNA2: proposal for a new channelopathy. Clin. Genet. 87, e1-e3. doi: 10.1111/cge.12542

Peng, Y., Lu, K., Li, Z., Zhao, Y., Wang, Y., Hu, B., et al. (2014). Blockade of Kv1.3 channels ameliorates radiation-induced brain injury. Neuro Oncol. 16, 528-539. doi: 10.1093/neuonc/not221

Pennington, M. W., Beeton, C., Galea, C. A., Smith, B. J., Chi, V., Monaghan, K. P., et al. (2009). Engineering a stable and selective peptide blocker of the Kv1.3 channel in T lymphocytes. Mol. Pharmacol. 75, 762-773. doi: 10.1124/mol.108. 052704

Pennington, M. W., Mahnir, V. M., Krafte, D. S., Zaydenberg, I., Byrnes, M. E., Khaytin, I., et al. (1996). Identification of three separate binding sites on SHK toxin, a potent inhibitor of voltage-dependent potassium channels in human T-lymphocytes and rat brain. Biochem. Biophys. Res. Commun. 219, 696-701. doi: 10.1006/bbrc.1996.0297

Pereira, L. E., Villinger, F., Wulff, H., Sankaranarayanan, A., Raman, G., and Ansari, A. A. (2007). Pharmacokinetics, toxicity, and functional studies of the selective Kv1.3 channel blocker 5-(4-phenoxybutoxy)psoralen in rhesus macaques. Exp. Biol. Med. 232, 1338-1354. doi: 10.3181/0705-rm-148
Perez-Verdaguer, M., Capera, J., Serrano-Novillo, C., Estadella, I., Sastre, D., and Felipe, A. (2016). The voltage-gated potassium channel Kv1.3 is a promising multitherapeutic target against human pathologies. Expert Opin. Ther. Targets 20, 577-591. doi: 10.1517/14728222.2016.1112792

Péter, M. Jr., Hajdu, P., Varga, Z., Damjanovich, S., Possani, L. D., Panyi, G., et al. (2000). Blockage of human T lymphocyte Kv1.3 channels by Pi1, a novel class of scorpion toxin. Biochem. Biophys. Res. Commun. 278, 34-37. doi: 10.1006/bbrc. 2000.3756

Pimentel, C., M’barek, S., Visan, V., Grissmer, S., Sampieri, F., Sabatier, J. M., et al. (2008). Chemical synthesis and 1H-NMR 3D structure determination of AgTx2-MTX chimera, a new potential blocker for Kv1.2 channel, derived from MTX and AgTx2 scorpion toxins. Protein Sci. 17, 107-118. doi: 10.1110/ps. 073122908

Poulopoulou, C., Markakis, I., Davaki, P., Tsaltas, E., Rombos, A., Hatzimanolis, A., et al. (2010). Aberrant modulation of a delayed rectifier potassium channel by glutamate in Alzheimer's disease. Neurobiol. Dis. 37, 339-348. doi: 10.1016/ j.nbd.2009.10.012

Prentis, P. J., Pavasovic, A., and Norton, R. S. (2018). Sea anemones: quiet achievers in the field of peptide toxins. Toxins 10:E36. doi: 10.3390/toxins10010036

Pucca, M. B., Bertolini, T. B., Cerni, F. A., Bordon, K. C., Peigneur, S., Tytgat, J., et al. (2016). Immunosuppressive evidence of Tityus serrulatus toxins Ts6 and Ts15: insights of a novel $\mathrm{K}(+)$ channel pattern in T cells. Immunology 147, 240-250. doi: 10.1111/imm.12559

Rangaraju, S., Chi, V., Pennington, M. W., and Chandy, K. G. (2009). Kv1.3 potassium channels as a therapeutic target in multiple sclerosis. Expert Opin. Ther. Targets 13, 909-924. doi: 10.1517/14728220903018957

Rangaraju, S., Dammer, E. B., Raza, S. A., Rathakrishnan, P., Xiao, H., Gao, T., et al. (2018). Identification and therapeutic modulation of a pro-inflammatory subset of disease-associated-microglia in Alzheimer's disease. Mol. Neurodegener. 13:24. doi: 10.1186/s13024-018-0254-8

Rangaraju, S., Gearing, M., Jin, L. W., and Levey, A. (2015). Potassium channel Kv1.3 is highly expressed by microglia in human Alzheimer's disease. J. Alzheimers Dis. 44, 797-808. doi: 10.3233/jad-141704

Rashid, M. H., Huq, R., Tanner, M. R., Chhabra, S., Khoo, K. K., Estrada, R., et al. (2014). A potent and Kv1.3-selective analogue of the scorpion toxin HsTX1 as a potential therapeutic for autoimmune diseases. Sci. Rep. 4:4509. doi: 10.1038/srep04509

Renisio, J. G., Romi-Lebrun, R., Blanc, E., Bornet, O., Nakajima, T., and Darbon, H. (2000). Solution structure of BmKTX, a K+ blocker toxin from the Chinese scorpion Buthus martensi. Proteins 38, 70-78. doi: 10.1002/(sici)10970134(20000101)38:1<70::aid-prot8>3.0.co;2-5

Rus, H., Cudrici, C., David, S., and Niculescu, F. (2006). The complement system in central nervous system diseases. Autoimmunity 39, 395-402. doi: 10.1080/ 08916930600739605

Rus, H., Pardo, C. A., Hu, L., Darrah, E., Cudrici, C., Niculescu, T., et al. (2005). The voltage-gated potassium channel Kv1.3 is highly expressed on inflammatory infiltrates in multiple sclerosis brain. Proc. Natl. Acad. Sci. U.S.A. 102, 1109411099. doi: 10.1073/pnas.0501770102

Sampson, T. R., Debelius, J. W., Thron, T., Janssen, S., Shastri, G. G., Ilhan, Z. E., et al. (2016). Gut microbiota regulate motor deficits and neuroinflammation in a model of Parkinson's disease. Cell 167, 1469.e12-1480.e12. doi: 10.1016/j.cell. 2016.11.018

Sanchez-Guajardo, V., Tentillier, N., and Romero-Ramos, M. (2015). The relation between alpha-synuclein and microglia in Parkinson's disease: recent developments. Neuroscience 302, 47-58. doi: 10.1016/j.neuroscience.2015. 02.008

Schmitz, A., Sankaranarayanan, A., Azam, P., Schmidt-Lassen, K., Homerick, D., Hansel, W., et al. (2005). Design of PAP-1, a selective small molecule Kv1.3 blocker, for the suppression of effector memory $\mathrm{T}$ cells in autoimmune diseases. Mol. Pharmacol. 68, 1254-1270. doi: 10.1124/mol.105.015669

Schwartz, A. B., Kapur, A., Wang, W., Huang, Z., Fardone, E., Palui, G., et al. (2017). Margatoxin-bound quantum dots as a novel inhibitor of the voltage-gated ion channel Kv1.3. J. Neurochem. 140, 404-420. doi: 10.1111/jnc.13891

Schweitz, H., Bruhn, T., Guillemare, E., Moinier, D., Lancelin, J. M., Beress, L., et al. (1995). Kalicludines and kaliseptine. Two different classes of sea anemone toxins for voltage sensitive $\mathrm{K}+$ channels. J. Biol. Chem. 270, 25121-25126. doi: $10.1074 /$ jbc. 270.42 .25121

Selkoe, D. J., and Hardy, J. (2016). The amyloid hypothesis of Alzheimer's disease at 25 years. EMBO Mol. Med. 8, 595-608. doi: 10.15252/emmm. 201606210 
Sitges, M., Possani, L. D., and Bayon, A. (1986). Noxiustoxin, a short-chain toxin from the Mexican scorpion Centruroides noxius, induces transmitter release by blocking K+ permeability. J. Neurosci. 6, 1570-1574. doi: 10.1523/jneurosci.0606-01570.1986

Takahashi, R. H., Capetillo-Zarate, E., Lin, M. T., Milner, T. A., and Gouras, G. K. (2010). Co-occurrence of Alzheimer's disease ss-amyloid and tau pathologies at synapses. Neurobiol. Aging 31, 1145-1152. doi: 10.1016/j.neurobiolaging.2008. 07.021

Tanner, M. R., Tajhya, R. B., Huq, R., Gehrmann, E. J., Rodarte, K. E., Atik, M. A., et al. (2017). Prolonged immunomodulation in inflammatory arthritis using the selective Kv1.3 channel blocker HsTX1[R14A] and its PEGylated analog. Clin. Immunol. 180, 45-57. doi: 10.1016/j.clim.2017.03.014

Tarcha, E. J., Chi, V., Munoz-Elias, E. J., Bailey, D., Londono, L. M., Upadhyay, S. K., et al. (2012). Durable pharmacological responses from the peptide ShK186, a specific Kv1.3 channel inhibitor that suppresses $\mathrm{T}$ cell mediators of autoimmune disease. J. Pharmacol. Exp. Ther. 342, 642-653. doi: 10.1124/jpet. 112.191890

Tarcha, E. J., Olsen, C. M., Probst, P., Peckham, D., Munoz-Elias, E. J., Kruger, J. G., et al. (2017). Safety and pharmacodynamics of dalazatide, a Kv1.3 channel inhibitor, in the treatment of plaque psoriasis: a randomized phase $1 \mathrm{~b}$ trial. PLoS One 12:e0180762. doi: 10.1371/journal.pone.0180762

Tegla, C. A., Cudrici, C., Rozycka, M., Soloviova, K., Ito, T., Singh, A. K., et al. (2011). C5b-9-activated, K(v)1.3 channels mediate oligodendrocyte cell cycle activation and dedifferentiation. Exp. Mol. Pathol. 91, 335-345. doi: 10.1016/j. yexmp.2011.04.006

Toldi, G., Vasarhelyi, B., Kaposi, A., Meszaros, G., Panczel, P., Hosszufalusi, N., et al. (2010). Lymphocyte activation in type 1 diabetes mellitus: the increased significance of Kv1.3 potassium channels. Immunol. Lett. 133, 35-41. doi: 10. 1016/j.imlet.2010.06.009

Trapp, B. D., Nishiyama, A., Cheng, D., and Macklin, W. (1997). Differentiation and death of premyelinating oligodendrocytes in developing rodent brain. J. Cell Biol. 137, 459-468. doi: 10.1083/jcb.137.2.459

Tubert, C., Taravini, I. R. E., Flores-Barrera, E., Sanchez, G. M., Prost, M. A., Avale, M. E., et al. (2016). Decrease of a current mediated by Kv1.3 channels causes striatal cholinergic interneuron hyperexcitability in experimental parkinsonism. Cell Rep. 16, 2749-2762. doi: 10.1016/j.celrep.2016.08.016

van Os, H. J., Mulder, I. A., Van Der Schaaf, I. C., Kappelle, L. J., Velthuis, B. K., Broersen, A., et al. (2016). Role of atherosclerosis, clot extent, and penumbra volume in headache during ischemic stroke. Neurology 87, 1124-1130. doi: 10.1212/wnl.0000000000003092

Verdura, E., Fons, C., Schluter, A., Ruiz, M., Fourcade, S., Casasnovas, C., et al. (2019). Complete loss of KCNA1 activity causes neonatal epileptic encephalopathy and dyskinesia. J. Med. Genet. doi: 10.1136/jmedgenet-2019106373

Veytia-Bucheli, J. I., Jimenez-Vargas, J. M., Melchy-Perez, E. I., SandovalHernandez, M. A., Possani, L. D., and Rosenstein, Y. (2018). Kv1.3 channel blockade with the Vm24 scorpion toxin attenuates the CD4(+) effector memory T cell response to TCR stimulation. Cell Commun. Signal. 16:45. doi: 10.1186/ s12964-018-0257-7

Wallace, A. N., Kansagra, A. P., Mceachern, J., Moran, C. J., Cross, D. T. III, and Derdeyn, C. P. (2016). Evolution of endovascular stroke therapies and devices. Expert Rev. Med. Devices 13, 263-270. doi: 10.1586/17434440.2016.1143772

Wickenden, A. D. (2002). Potassium channels as anti-epileptic drug targets. Neuropharmacology 43, 1055-1060. doi: 10.1016/s0028-3908(02)00237-x
Wittner, L., Magloczky, Z., Borhegyi, Z., Halasz, P., Toth, S., Eross, L., et al. (2001). Preservation of perisomatic inhibitory input of granule cells in the epileptic human dentate gyrus. Neuroscience 108, 587-600. doi: 10.1016/s0306-4522(01) 00446-8

Wu, B., Wu, B. F., Feng, Y. J., Tao, J., and Ji, Y. H. (2016). Mapping the interaction anatomy of BmP02 on Kv1.3 Channel. Sci. Rep. 6:29431. doi: 10.1038/srep 29431

Wulff, H., Calabresi, P. A., Allie, R., Yun, S., Pennington, M., Beeton, C., et al. (2003). The voltage-gated $\mathrm{Kv} 1.3 \mathrm{~K}(+)$ channel in effector memory T cells as new target for MS. J. Clin. Invest. 111, 1703-1713. doi: 10.1172/jci16921

Wulff, H., Castle, N. A., and Pardo, L. A. (2009). Voltage-gated potassium channels as therapeutic targets. Nat. Rev. Drug Discov. 8, 982-1001. doi: 10.1038/nrd 2983

Wulff, H., Christophersen, P., Colussi, P., Chandy, K. G., and Yarov-Yarovoy, V. (2019). Antibodies and venom peptides: new modalities for ion channels. Nat. Rev. Drug Discov. 18, 339-357. doi: 10.1038/s41573-019-0013-8

Wulff, H., and Zhorov, B. S. (2008). K+ channel modulators for the treatment of neurological disorders and autoimmune diseases. Chem. Rev. 108, 1744-1773. doi: $10.1021 / \mathrm{cr} 078234 \mathrm{p}$

Yang, W., Feng, J., Wang, B., Cao, Z., Li, W., Wu, Y., et al. (2014). BF9, the first functionally characterized snake toxin peptide with Kunitz-type protease and potassium channel inhibiting properties. J. Biochem. Mol. Toxicol. 28, 76-83. doi: 10.1002/jbt.21538

Zhang, B., Gaiteri, C., Bodea, L. G., Wang, Z., Mcelwee, J., Podtelezhnikov, A. A., et al. (2013). Integrated systems approach identifies genetic nodes and networks in late-onset Alzheimer's disease. Cell 153, 707-720. doi: 10.1016/j.cell.2013. 03.030

Zhao, Y., Huang, J., Yuan, X., Peng, B., Liu, W., Han, S., et al. (2015). Toxins targeting the Kv1.3 channel: potential immunomodulators for autoimmune diseases. Toxins 7, 1749-1764. doi: 10.3390/toxins7051749

Zheng, L. T., Hwang, J., Ock, J., Lee, M. G., Lee, W. H., and Suk, K. (2008). The antipsychotic spiperone attenuates inflammatory response in cultured microglia via the reduction of proinflammatory cytokine expression and nitric oxide production. J. Neurochem. 107, 1225-1235. doi: 10.1111/j.1471-4159. 2008.05675.x

Zhou, Q. L., Wang, T. Y., Li, M., and Shang, Y. X. (2018). Alleviating airway inflammation by inhibiting ERK-NF-kappaB signaling pathway by blocking Kv1.3 channels. Int. Immunopharmacol. 63, 110-118. doi: 10.1016/j.intimp. 2018.07.009

Zhu, L., Gao, B., Luo, L., and Zhu, S. (2012). Two dyad-free Shaker-type K(+) channel blockers from scorpion venom. Toxicon 59, 402-407. doi: 10.1016/j. toxicon.2011.11.016

Conflict of Interest: The authors declare that the research was conducted in the absence of any commercial or financial relationships that could be construed as a potential conflict of interest.

Copyright (c) 2020 Wang, Li, Guo, Zhang, Zhang, Zhu, Cheng, Yu, Ji and Tao. This is an open-access article distributed under the terms of the Creative Commons Attribution License (CC BY). The use, distribution or reproduction in other forums is permitted, provided the original author(s) and the copyright owner(s) are credited and that the original publication in this journal is cited, in accordance with accepted academic practice. No use, distribution or reproduction is permitted which does not comply with these terms. 